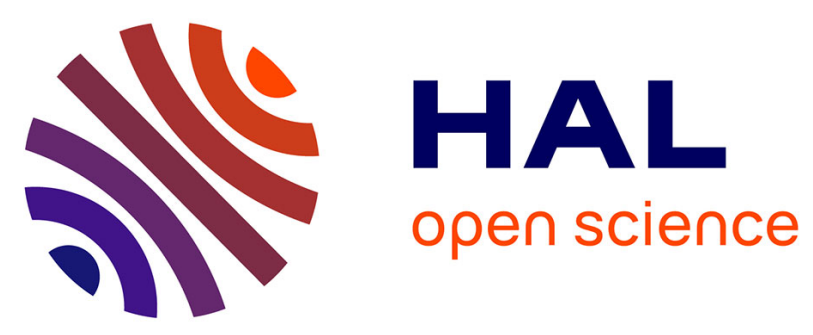

\title{
SMOKING IN PREGNANCY AND DISRUPTIVE BEHAVIOUR IN 3-YEAR OLD BOYS AND GIRLS: AN ANALYSIS OF THE UK MILLENNIUM COHORT STUDY
}

Jayne Hutchinson, Kate E Pickett, Josephine Green, Lauren S Wakschlag

\section{To cite this version:}

Jayne Hutchinson, Kate E Pickett, Josephine Green, Lauren S Wakschlag. SMOKING IN PREGNANCY AND DISRUPTIVE BEHAVIOUR IN 3-YEAR OLD BOYS AND GIRLS: AN ANALYSIS OF THE UK MILLENNIUM COHORT STUDY. Journal of Epidemiology and Community Health, 2009, 64 (01), pp.82-n/a. 10.1136/jech.2009.089334 . hal-00490560

\section{HAL Id: hal-00490560 https://hal.science/hal-00490560}

Submitted on 9 Jun 2010

HAL is a multi-disciplinary open access archive for the deposit and dissemination of scientific research documents, whether they are published or not. The documents may come from teaching and research institutions in France or abroad, or from public or private research centers.
L'archive ouverte pluridisciplinaire HAL, est destinée au dépôt et à la diffusion de documents scientifiques de niveau recherche, publiés ou non, émanant des établissements d'enseignement et de recherche français ou étrangers, des laboratoires publics ou privés. 


\title{
SMOKING IN PREGNANCY AND DISRUPTIVE BEHAVIOUR IN 3-YEAR OLD BOYS AND GIRLS: AN ANALYSIS OF THE UK MILLENNIUM COHORT STUDY
}

\author{
Jayne Hutchinson, ${ }^{1}$ Kate E. Pickett, ${ }^{1,2}$ Josephine Green, ${ }^{1,2}$ Lauren S. Wakschlag ${ }^{3}$ \\ ${ }^{1}$ Department of Health Sciences, University of York, UK \\ ${ }^{2}$ Hull-York Medical School, UK \\ ${ }^{3}$ Institute for Juvenile Research, Department of Psychiatry, University of Illinois at \\ Chicago, Illinois, USA
}

\section{Please address correspondence to:}

Jayne Hutchinson

Nutritional Epidemiology Group

Faculty of Medicine

University of Leeds

Room 8.01, Level 8, Worsley Building

Leeds LS2 9JT

Email address: umjh@leeds.ac.uk

Word count: 3188

Word count for abstract: 273 


\begin{abstract}
Background: Maternal smoking during pregnancy has been consistently associated with disruptive behaviour in male offspring, however results for girls are inconsistent and little is known about emergent patterns in young children. Additionally, it is unclear whether maternal smoking is independently associated in offspring with hyperactivityinattention or only when it co-occurs with conduct problems. Further, few studies have controlled for a broad range of maternal psychosocial problems.
\end{abstract}

Methods: We analysed associations between self-reported smoking in pregnancy and maternal reports of externalising behaviour in more than 13,000 3-year old boys and girls in the UK Millennium Cohort Study. Conduct and hyperactivity-inattention problems were assessed using the Strength and Difficulties Questionnaire.

Results: Boys whose mothers persistently smoked throughout pregnancy were at significant risk of conduct and hyperactivity-inattention problems compared to sons of non-smokers: the effect was stronger for heavy smokers. After excluding children with co-occurring problems, conduct-only problems remained a significant risk for sons of heavy smokers, $\mathrm{OR}(95 \% \mathrm{CI})=1.92(1.29$ to 2.86$)$; and hyperactivity-inattention-only for sons of light or heavy smokers, $\mathrm{OR}(95 \% \mathrm{CI})=1.79(1.27$ to 2.51$)$ and $1.64(1.10$ to 2.46$)$. Daughters of light or heavy smokers were at significant risk of conduct-only problems, $\mathrm{OR}(95 \% \mathrm{CI})=1.73(1.14$ to 2.61$)$ and $1.73(1.06$ to 2.83$)$. Relative to non-smokers, daughters of pregnancy quitters had significantly reduced odds of having conduct $0.61(0.39$ to 0.97$)$ or co-occurring problems $0.26(0.08$ to 0.82$)$, although only 79 and 20 girls met these criteria, respectively. All findings were robust to controlling for key social and psychosocial factors. 
Conclusions: Associations between maternal smoking during pregnancy and disruptive behaviour in 3 year old children vary by sex, smoking status and whether or not conduct or hyperactivity problems occur together or separately. 
Smoking during pregnancy increases the risk of ectopic pregnancy, miscarriage, perinatal death, preterm delivery and low birth-weight. ${ }^{1}$ In addition, prenatal smoking has been consistently associated across different populations, study designs and outcome measures with externalising problem behaviour in male offspring, i.e. hyperactivity and conduct disorder. ${ }^{2}$ Evidence reviewed by Wakschlag et al $^{3}$ suggests a developmental pathway for the latter association, characterised by oppositional disorders in young children, conduct disorders and delinquency in older children and adolescents.

Evidence supporting an exposure-related early developmental pathway includes findings that smoking during pregnancy is associated with child-onset, rather than adolescentonset conduct problems, ${ }^{45}$ and evidence that the elevated risk of externalising problems remains constant during childhood. ${ }^{6}$ Exposure-related externalising problem behaviour has also been identified in pre-school children, ${ }^{78}$ and linked to escalations in physical aggression, a component of conduct disorder. ${ }^{910-12}$ Negativity and difficult temperament in infants may also be part of the developmental pathway. ${ }^{13} 14$

Smoking during pregnancy has been consistently associated with conduct symptoms in male offspring of school age, ${ }^{415-21}$ but inconsistently in school-aged girls. ${ }^{41617,51519}$ Significant associations with physical aggression and/or defiance have been found in both pre-school boys and girls. ${ }^{710-12}$ However, many studies appear to have had insufficient power to systematically test for interactions with gender, or have only sampled boys. ${ }^{6711}$ $1618-21$ 
Attention deficit hyperactivity disorder (ADHD) in offspring has been associated with smoking during pregnancy in some studies, ${ }^{22-26}$ but not others. ${ }^{51920}$ It is possible that this association only exists because ADHD tends to co-occur with exposure related conduct or oppositional defiant symptoms. In the two studies that have assessed ADHDonly symptoms, exposure was not significantly associated with ADHD-only in pre-school children without physical aggression symptoms, nor in 7-19 year olds without oppositional defiant disorder symptoms. ${ }^{921}$ Therefore we hypothesized, in our study, that hyperactivity-inattention would not be independently associated with smoking during pregnancy but that indirect associations would be found when it co-occurred with conduct problems.

Women who smoke during pregnancy are more likely to live in more difficult circumstances, to have low socio-economic status, lower social support, and experience more stressful life events. ${ }^{27}$ These psychosocial factors are also risk factors for disruptive behaviour problems in children. ${ }^{3}$ Additionally, poor adaptive functioning increases with increased prenatal smoking. ${ }^{29}$ Nevertheless, only one previous study of smoking in pregnancy and disruptive behaviour has controlled for this. ${ }^{12}$

To our knowledge no studies of pre-school children have previously compared offspring of persistent smokers and those who quit, neither is it possible to distinguish between heavy and light smokers in many studies. In addition to identifying dose-response relationships, the potential importance of correctly classifying exposure was shown in a study which found that quitters were less likely to have temperamentally difficult infants compared to both persistent smokers and non-smokers. ${ }^{14}$ Since smoking patterns vary 
across pregnancy, ${ }^{30} 31$ retrospective assessment of exposure, such as that used in the Millennium Cohort Study (MCS), can potentially identify exposure better than infrequent or untimely prospective questioning or biochemical analysis. ${ }^{32}$

In this study we capitalize on the large sample size of the MCS with substantial numbers of persistent smokers (23\%), and the ability to categorise smoking patterns during pregnancy. We aim to build on existing research by (a) examining sex differences in relationships between categories of smoking in pregnancy (quitting, light and heavy persistent smoking) and behaviour problems at 3 years of age; (b) testing robustness to potential confounding from key psychosocial domains empirically established as risk factors for persistent pregnancy smoking; and (c) investigating whether smoking exposure effects are specific to conduct problems, hyperactivity problems or their cooccurrence.

\section{METHODS}

\section{Study population and sample}

This research used pre-gathered data from The Millennium Cohort Study, a large, prospective, population-based study of children born in 2000 and 2001, selected from the whole UK Child Benefit Register ${ }^{334}$ The cohort was initiated to monitor the effects of new policies and structures on child development and families. To this end families from areas with high levels of child poverty, and from areas with high proportions of ethnic minority residents, were over-sampled. The response rate for the first wave of data collection was $72 \%$; non-respondents were more likely to be without fixed residence, living in ethnic minority areas in England, or living in disadvantaged areas. The first 
wave of data collection, which took place when infants were aged 9 months on average, included 18,819 infants in 18,552 families; of these 14,898 (80\%) families participated in the second wave when children were 3 years old. Data was gathered in the family home by computer assisted interview.

For our study, we excluded families with multiple births ( $=202$ families), those lacking pregnancy smoking information $(n=8)$ and non-natural mother $(n=334)$, giving an eligible sample of 14,354 mother-child pairs. Further exclusions were made if insufficient

information was provided for the Strength and Difficulties Questions (SDQ), ${ }^{35}$ producing analytical samples of 13,788 and 13,654 families for the conduct and hyperactivity scales respectively.

\section{Measurement of maternal smoking during pregnancy}

Mothers were asked how many cigarettes they smoked per day before pregnancy and the number smoked before and after any change. Information was collected on average 9 months after birth. Mothers were classified into the following smoking categories: (1) Never smoked during pregnancy; (2) Quit smoking during pregnancy; (3) Continuous light smoker during pregnancy (less than 10 cigarettes per day); (4) Continuous heavy smoker during pregnancy (10+ cigarettes per day).

\section{Measurement of child behaviour}

Mothers rated their child's behaviour at age 3 using questions from the SDQ, widely used to assess 3-16 year olds. It consists of 25 items divided into 5 sub-scales of 5 items each, 
using 4-point Likert scales. ${ }^{35}$ In this study we examine the 2 disruptive behaviour subscales: conduct problems and hyperactivity-inattention problems.

The structure of questioning was "What is your child like?" followed by a statement e.g.: "Often argumentative with adults". Respondents were asked to indicate the appropriate answer: "Not true" (scoring 0) "Somewhat true" (scoring 1), "Certainly true" (scoring 2) or “Can't say" (scored as missing).

The conduct problem statements were: "Often has temper tantrums or hot tempers"; "Generally obedient, usually does what adults request"; "Often fights with other children or bullies them"; "Often argumentative with adults"; "Can be spiteful to others". (Note: the last two statements replaced "Often lies or cheats" and "Steals from home, school or elsewhere" used in the SDQ for school aged children.) The hyperactivity-inattention problem statements were: "Restless, overactive, cannot stay still for long"; "Constantly fidgeting or squirming"; "Easily distracted, concentration wanders"; "Can stop and think things out before acting"; "Sees tasks through to the end, good attention span".

If a mother answered two or fewer questions out of a total of 5 in each sub-scale then the sub-scale score for this child was counted as missing. The mean sub-scale scores for the remaining children were prorated to 5 items if at least 3 out of 5 items were completed (www.sdqinfo.com). ${ }^{35}$ Scores were dichotomised into normal and abnormal behaviour, using the nearest whole number mean score as a cut-off point, to classify approximately the top $10 \%$ of the weighted sample as having abnormal behaviour (www.sdqinfo.com). ${ }^{35}$ 
These dichotomised categories were used to test the hypothesis that smoking during pregnancy increases the risk of behaviour problems in children.

\section{Potential confounding factors}

Potential confounders were examined and grouped into 5 domains as listed in table 1. Unless otherwise specified, socio-demographic variables were measured at wave1 (W1) and variables for the other domains were measured at wave 2 (W2). All measures were self-reported by mothers. Additional details and references relating to variables in the domains below can be found in a related study of the psychosocial context of pregnancy smoking in this cohort. ${ }^{29}$

Socio-demographic factors: mother's age (years) at index child's birth; number of children in the household at wave 2; mother's ethnicity; family stability based on change of partner or change of single parent status between waves. Three measures of socioeconomic status were household poverty (household income below $60 \%$ of the median); low maternal education (less than GCSE A-C or no UK qualifications at wave 2); working class (routine or semi-routine occupation), using the highest of the mother's and/or father's social class (NS-SEC).

Problematic relationships as listed in table 1 included problematic relationships with the mother's family of origin; problematic relationships with peers; and those with partner.

Problematic parenting examined smacking child daily or weekly; strict parenting style; and lacking discipline. We also examined two proxy measures of mothers' conformity to 
societal norms: having no wish to instil obedience or respect for authority or elders; having no wish to instil religious values in their children.

Poor adaptive functioning measured poor daily functioning as having no phone; having no bank account; having difficulty managing finances; having a very disorganised household; ever being homeless since the birth of the child. Poor general functioning variables were: feeling a lack of control over life; low self-esteem; low satisfaction with life.

Poor maternal and infant health and health-related behaviour variables included those relating to current psychological distress (measured using 6 items from the Psychological Distress Scale ${ }^{36}$ ); history of depression; alcohol or drug problems; plus poor pre-natal and post-natal health behaviours as listed in table 1 .

\section{Statistical analysis}

All analyses were weighted using Stata SE version 10 survey commands to correct for over-sampling of disadvantaged areas to produce UK representative results. All counts reported in tables are un-weighted and percentages are weighted. Characteristics of mothers and infants by smoking status were described using means and proportions, differences were tested by Wald tests and chi-square tests, respectively.

Unadjusted odds ratios were estimated separately for boys and girls for associations between pregnancy smoking status and behaviour. Our approach to adjustment was designed to produce parsimonious models. We first estimated domain-specific multiple 
logistic regression models, including all potential confounding factors within that domain for each sex-behaviour association. Backwards stepwise elimination produced restricted models for each of the five domains. These reduced sets of confounders were then included in final multiple logistic regression models for each sex-behaviour association. We also tested the statistical significance of a sex-exposure interaction in models including both boys and girls.

Multinomial logistic regression was performed to test sex-specific associations between smoking and conduct-only, hyperactivity-inattention-only, and co-occurring conduct and hyperactivity-inattention problems. To determine specific behavioural effects of smoking exposure, children with each abnormal behaviour type were compared to children who had neither conduct nor hyperactivity-inattention problems.

\section{Results}

Almost $10 \%$ of women reported smoking heavily throughout pregnancy, $12.5 \%$ were light smokers, and $12.4 \%$ quit during pregnancy. Of those who quit $92 \%$ stopped during

$1^{\text {st }}$ trimester and $7 \%$ in $2^{\text {nd }}$ trimester. Maternal smoking status was significantly associated with all socio-demographic characteristics and also with the majority of maternal problems; less favourable characteristics being significantly associated with more persistent and heavier smoking (table 1). 
Table 1 Characteristics of mothers and infants by maternal smoking status during pregnancy

\begin{tabular}{|c|c|c|c|c|}
\hline & Never smoked & Quit smoking & Light smoker & Heavy smoker \\
\hline & $\begin{array}{c}\mathrm{N}=9,401 \\
65.5 \%\end{array}$ & $\begin{array}{c}\mathrm{N}=1,787 \\
12.4 \%\end{array}$ & $\begin{array}{c}\mathrm{N}=1,795 \\
12.5 \%\end{array}$ & $\begin{array}{c}\mathrm{N}=1,371 \\
9.6 \%\end{array}$ \\
\hline Socio-demographic & Mean (SE) & Mean (SE) & Mean (SE) & Mean (SE) \\
\hline Maternal age (years) at birth * & $30.6(0.12)$ & $27.2(0.19)$ & $26.7(0.18)$ & $27.1(0.17)$ \\
\hline \multirow[t]{2}{*}{ Children in Household W2 $*$} & $2.2(0.01)$ & $1.9(0.02)$ & $2.1(0.03)$ & $2.5(0.04)$ \\
\hline & $\%$ of smoke cat. & $\%$ of smoke cat. & $\%$ of smoke cat. & $\%$ of smoke cat. \\
\hline Family stability between waves*: & & & & \\
\hline Same Partner, married & $76.6 \%$ & $52.4 \%$ & $38.4 \%$ & $32.4 \%$ \\
\hline Same Partner, cohabiting & $13.6 \%$ & $21.9 \%$ & $27.7 \%$ & $29.6 \%$ \\
\hline Change of partner & $0.7 \%$ & $1.2 \%$ & $1.2 \%$ & $2.3 \%$ \\
\hline Split from partner, now single & $3.5 \%$ & $7.1 \%$ & $8.7 \%$ & $8.7 \%$ \\
\hline Previously single, now partnered & $1.3 \%$ & $4.1 \%$ & $5.4 \%$ & $7.1 \%$ \\
\hline Single mother at both waves & $4.3 \%$ & $13.3 \%$ & $18.6 \%$ & $19.9 \%$ \\
\hline Below $60 \%$ median poverty $*$ & $17.3 \%$ & $26.3 \%$ & $44.5 \%$ & $56.8 \%$ \\
\hline $\begin{array}{l}\text { Less than GCSE A-C, or no UK } \\
\text { qualifications W } 2 *\end{array}$ & $18.5 \%$ & $24.4 \%$ & $40.7 \%$ & $54.8 \%$ \\
\hline \multirow[t]{2}{*}{ Working class family * } & $13.5 \%$ & $24.4 \%$ & $36.2 \%$ & $49.3 \%$ \\
\hline & $\%$ of ethnic grp. & $\%$ of ethnic grp. & $\%$ of ethnic grp. & $\%$ of ethnic grp \\
\hline Maternal ethnic group*: & & & & \\
\hline White & $65.3 \%$ & $13.7 \%$ & $12.1 \%$ & $8.9 \%$ \\
\hline Mixed & $60.3 \%$ & $13.8 \%$ & $17.3 \%$ & $8.6 \%$ \\
\hline Indian & $92.8 \%$ & $5.7 \%$ & $0.7 \%$ & $0.8 \%$ \\
\hline Pakistani/Bangladeshi & $95.5 \%$ & $1.3 \%$ & $2.5 \%$ & $0.7 \%$ \\
\hline Black/Black British & $78.8 \%$ & $10.1 \%$ & $9.0 \%$ & $2.1 \%$ \\
\hline Other & $85.6 \%$ & $7.5 \%$ & $4.5 \%$ & $2.4 \%$ \\
\hline Problematic relationships & $\%$ of smoke cat. & $\%$ of smoke cat. & $\%$ of smoke cat. & $\%$ of smoke cat. \\
\hline Lived away from home pre $17 *$ & $10.3 \%$ & $17.7 \%$ & $23.0 \%$ & $29.9 \%$ \\
\hline Spent any time in care as child* & $0.6 \%$ & $1.5 \%$ & $2.1 \%$ & $5.5 \%$ \\
\hline Maternal parents separated $*$ & $23.8 \%$ & $38.0 \%$ & $42.0 \%$ & $48.6 \%$ \\
\hline Never sees mother if alive* & $1.6 \%$ & $2.1 \%$ & $2.2 \%$ & $3.8 \%$ \\
\hline Never sees father if alive* & $5.6 \%$ & $7.9 \%$ & $9.9 \%$ & $13.2 \%$ \\
\hline No time with friends \# & $18.2 \%$ & $15.5 \%$ & $16.8 \%$ & $20.0 \%$ \\
\hline No-one to share feelings $*$ & $4.8 \%$ & $7.8 \%$ & $9.0 \%$ & $14.0 \%$ \\
\hline No visits to/by other parents * & $6.4 \%$ & $7.3 \%$ & $8.0 \%$ & $13.6 \%$ \\
\hline Poor child-mother relationship * & $8.6 \%$ & $12.2 \%$ & $16.7 \%$ & $24.5 \%$ \\
\hline Low partner satisfaction * & $14.8 \%$ & $22.6 \%$ & $24.1 \%$ & $31.7 \%$ \\
\hline Partner perpetrated violence * & $3.0 \%$ & $5.4 \%$ & $7.2 \%$ & $8.9 \%$ \\
\hline $\begin{array}{l}\text { Ever lived with more than one } \\
\text { partner* }\end{array}$ & $26.7 \%$ & $38.3 \%$ & $43.0 \%$ & $48.1 \%$ \\
\hline Problematic Parenting & $\%$ of smoke cat. & $\%$ of smoke cat. & $\%$ of smoke cat. & $\%$ of smoke cat. \\
\hline Lacking parenting competence * & $2.5 \%$ & $3.8 \%$ & $3.6 \%$ & $5.5 \%$ \\
\hline Smacking daily or weekly \# & $9.1 \%$ & $8.0 \%$ & $10.1 \%$ & $11.7 \%$ \\
\hline Lack of discipline * & $13.3 \%$ & $12.5 \%$ & $17.0 \%$ & $18.1 \%$ \\
\hline $\begin{array}{l}\text { Don't instil either obedience or } \\
\text { respect }\end{array}$ & $9.2 \%$ & $13.6 \%$ & $16.1 \%$ & $15.7 \%$ \\
\hline Don't instil religious values * & $35.6 \%$ & $51.3 \%$ & $62.0 \%$ & $66.2 \%$ \\
\hline Poor adaptive functioning & $\%$ of smoke cat. & $\%$ of smoke cat. & $\%$ of smoke cat. & $\%$ of smoke cat. \\
\hline Low sense of control W1* & $10.4 \%$ & $18.0 \%$ & $23.3 \%$ & $30.9 \%$ \\
\hline Low satisfaction with life * & $6.8 \%$ & $11.8 \%$ & $16.8 \%$ & $22.1 \%$ \\
\hline Low self esteem $\mathrm{W} 1 *$ & $8.35 \%$ & $9.9 \%$ & $12.3 \%$ & $17.5 \%$ \\
\hline Ever homeless (since the birth) * & $1.3 \%$ & $3.1 \%$ & $3.5 \%$ & $4.6 \%$ \\
\hline No phone $\mathrm{W} 1 *$ & $1.6 \%$ & $3.8 \%$ & $5.2 \%$ & $7.3 \%$ \\
\hline Difficulty managing Finances * & $6.9 \%$ & $10.1 \%$ & $13.6 \%$ & $15.8 \%$ \\
\hline
\end{tabular}




\begin{tabular}{|l|c|c|c|c|}
\hline No bank account W1* & $4.5 \%$ & $7.5 \%$ & $16.3 \%$ & $24.5 \%$ \\
Very disorganised household * & $1.5 \%$ & $2.0 \%$ & $2.8 \%$ & $4.6 \%$ \\
\hline Health related Behaviours & $\%$ of smoke cat. & $\%$ of smoke cat. & $\%$ of smoke cat. & $\%$ of smoke cat. \\
\hline Current psychological distress * & $7.7 \%$ & $11.6 \%$ & $16.2 \%$ & $23.0 \%$ \\
History of Depression * & $22.6 \%$ & $35.5 \%$ & $40.0 \%$ & $47.4 \%$ \\
Drink Problem * & $3.3 \%$ & $7.2 \%$ & $6.4 \%$ & $8.1 \%$ \\
Drug Problem * & $1.3 \%$ & $7.23 \%$ & $9.15 \%$ & $11.3 \%$ \\
Limiting long term illness * & $19.8 \%$ & $20.7 \%$ & $23.1 \%$ & $30.9 \%$ \\
Unplanned pregnancy W1 * & $31.5 \%$ & $50.0 \%$ & $57.5 \%$ & $63.0 \%$ \\
Late entry to antenatal care W1 * & $19.8 \%$ & $23.0 \%$ & $25.9 \%$ & $24.7 \%$ \\
Not attempted breast feeding W1* & $20.2 \%$ & $28.0 \%$ & $42.4 \%$ & $51.6 \%$ \\
Incomplete immunisations E* & $3.5 \%$ & $4.7 \%$ & $6.0 \%$ & $9.4 \%$ \\
Postnatal smoking near child E* & $11.0 \%$ & $20.3 \%$ & $41.4 \%$ & $64.9 \%$ \\
Drinking during pregnancyW1 & $34.0 \%$ & $37.2 \%$ & $34.0 \%$ & $34.2 \%$ \\
& & & & \\
Low birth weight $(<2500 \mathrm{~g}) \mathrm{W} 1 *$ & $4.8 \%$ & $5.0 \%$ & $8.9 \%$ & $10.1 \%$ \\
Preterm delivery $(<37$ wks)W1\# & $6.4 \%$ & $6.1 \%$ & $8.7 \%$ & $8.9 \%$ \\
\hline
\end{tabular}

Differences statistically significant at $*=p<0.001,{ }^{\wedge}=p<0.01, \#=p<0.05$

$\mathrm{W} 1=$ recorded at wave 1 , about 9 months after birth

$\mathrm{W} 2=$ recorded at wave 2, about 3 years after birth

$\mathrm{E}=$ recorded at either wave

The unadjusted analyses show statistically significant associations between risks of problem behaviour and both light and heavy smoking. Dose-response relationships were significant for conduct symptoms in boys and were apparent but non-significant for the other relationships (Table 2). Although an unadjusted statistically significant interaction was found between heavy smoking and sex in relation to conduct scored as a continuous variable, no individual interaction term was significant when conduct or hyperactivityimpulsivity were used as dichotomous outcomes in logistic regression models.

Nevertheless, based on previous literature we proceeded to perform adjusted stratified analyses.

Table 2 shows that for boys, after adjustment for all socio-demographic, psychosocial and parenting domains, significant associations for individual exposure categories remained and non-significant dose-response relationships remained between persistent smoking in pregnancy and conduct problems (light smoking $\mathrm{OR}=1.44,95 \% \mathrm{CI}$ : $1.01-2.06, \mathrm{p}=0.044$; heavy smoking $\mathrm{OR}=1.80,95 \% \mathrm{CI}: 1.28-2.54, \mathrm{p}=0.001$ ), and also hyperactivity- 
inattention problems (light smoking OR $=1.56,95 \% \mathrm{CI}: 1.12-2.15, \mathrm{p}=0.016$; heavy

smoking $\mathrm{OR}=1.62,95 \% \mathrm{CI}: 1.13-2.33, \mathrm{p}=0.009$ respectively). Daughters of mothers who quit smoking during pregnancy had reduced risks of conduct problems compared to daughters of non-smokers which only became significant after adjusting for all social and psychosocial domains $(\mathrm{OR}=0.61,95 \% \mathrm{CI}: 0.39-0.97, \mathrm{p}=0.035)$.

Table 2 Odds ratios for behaviour problems at age 3 by maternal smoking in pregnancy

\begin{tabular}{|c|c|c|c|c|}
\hline Behaviour Problems & $\begin{array}{l}\text { Never } \\
\text { smoked }\end{array}$ & $\begin{array}{l}\text { Quit smoking } \\
\text { OR }(95 \% \text { CI })\end{array}$ & $\begin{array}{l}\text { Light smoker } \\
\text { OR }(95 \% \text { CI })\end{array}$ & $\begin{array}{l}\text { Heavy smoker } \\
\text { OR }(95 \% \text { CI })\end{array}$ \\
\hline \multicolumn{5}{|l|}{$\begin{array}{l}\text { BOYS } \\
\text { unadjusted }\end{array}$} \\
\hline Conduct & Ref & $1.54(1.16 \text { to } 2.04)^{\wedge}$ & $2.66(2.07 \text { to } 3.42)^{*}$ & $4.50(3.60 \text { to } 5.65)^{*}$ \\
\hline Hyperactivity-inattention & Ref & $1.09(0.86$ to 1.39$)$ & $1.64(1.35 \text { to } 2.02)^{*}$ & $2.21(1.74 \text { to } 2.79)^{*}$ \\
\hline \multicolumn{5}{|l|}{ Fully adjusted } \\
\hline Conduct & Ref & $1.21(0.83$ to 1.78$)$ & 1.44 (1.01 to 2.06$) \#$ & $1.80(1.28 \text { to } 2.54)^{\wedge}$ \\
\hline Hyperactivity-inattention & Ref & $0.94(0.67$ to 1.32$)$ & $1.56(1.12 \text { to } 2.15)^{\wedge}$ & $1.62(1.13 \text { to } 2.33)^{\wedge}$ \\
\hline \multicolumn{5}{|l|}{$\begin{array}{l}\text { GIRLS } \\
\text { unadjusted }\end{array}$} \\
\hline Conduct & Ref & $1.14(0.83$ to 1.55$)$ & $2.28(1.70 \text { to } 3.07)^{*}$ & $3.45(2.69 \text { to } 4.44)^{*}$ \\
\hline Hyperactivity-inattention & Ref & $1.31(0.98$ to 1.73$)$ & $1.80(1.36 \text { to } 2.38)^{*}$ & $2.28(1.71 \text { to } 3.04)^{*}$ \\
\hline \multicolumn{5}{|l|}{ Fully adjusted } \\
\hline Conduct & Ref & $0.61(0.39$ to 0.97$) \#$ & $1.06(0.70$ to 1.63$)$ & $1.34(0.88$ to 2.03$)$ \\
\hline Hyperactivity-inattention & Ref & $0.96(0.66$ to 1.41$)$ & $1.28(0.90$ to 1.81$)$ & $1.17(0.79$ to 1.72$)$ \\
\hline
\end{tabular}

Differences statistically significant at $*=p<0.001, \wedge=p<0.01, \#=p<0.05$

Conduct problems $=$ scores of 6 or above out of 10 (top $10.3 \%$ male, $8.7 \%$ female)

Hyperactivity-inattention problems $=$ scores of 7 or above (top $14.9 \%$ male, $9.2 \%$ female)

\section{Co-occurring and non-co-occurring behaviour problems}

When comparing the risk of having a single type of behaviour problem (either conduct or hyperactivity-inattention) with having neither behaviour problem, and after adjusting for all covariates, associations with heavy smoking in pregnancy were statistically significant (Table 3$)$ for conduct-only problems (OR = 1.92, 95\% CI: 1.29-2.86, $\mathrm{p}=0.001)$, hyperactivity-inattention-only problems $(\mathrm{OR}=1.64,95 \% \mathrm{CI}: 1.10-2.46$, $\mathrm{p}=0.016)$, and co-occurring problems in boys $(\mathrm{OR}=1.76,95 \% \mathrm{CI}: 1.05-2.94, \mathrm{p}=0.032)$. Statistically significant associations were also found between light smoking and hyperactivity-inattention-only problems $(\mathrm{OR}=1.79,95 \% \mathrm{CI}: 1.27-2.51, \mathrm{p}=0.001)$. For 
girls, light and heavy smoking in pregnancy were significantly associated with conduct-

only problems (Light smoking $\mathrm{OR}=1.73,95 \% \mathrm{CI}: 1.14$ to $2.61, \mathrm{p}=0.009$; heavy smoking $\mathrm{OR}=1.73,95 \% \mathrm{CI}: 1.06$ to $2.83, \mathrm{p}=0.028$ ). Additionally, girls whose mothers quit smoking in pregnancy were significantly less likely to have co-occurring problems than girls whose mothers never smoked $(\mathrm{OR}=0.26,95 \% \mathrm{CI}: 0.08$ to $0.82, \mathrm{p}=0.022)$. Table 4 shows that conduct-only symptoms are as prevalent in girls as they are in boys at 3 years old.

Table 3 Adjusted odds ratios of conduct-only, hyperactivity-inattention-only and cooccurring problems by maternal smoking status, with children having neither problem behaviour as reference group.

\begin{tabular}{|c|c|c|c|c|}
\hline & $\begin{array}{l}\text { Never } \\
\text { smoked }\end{array}$ & $\begin{array}{l}\text { Quit smoking } \\
\text { OR }(95 \% \mathrm{CI})\end{array}$ & $\begin{array}{l}\text { Light smoker } \\
\text { OR }(95 \% \text { CI })\end{array}$ & $\begin{array}{l}\text { Heavy smoker } \\
\text { OR }(95 \% \text { CI })\end{array}$ \\
\hline BOYS & & & & \\
\hline Conduct-only & Ref & $1.14(0.71$ to 1.85$)$ & $1.44(0.92$ to 2.26$)$ & $1.92(1.29 \text { to } 2.86)^{\wedge}$ \\
\hline Hyperactivity-only & Ref & $0.89(0.62$ to 1.26$)$ & $1.79(1.27 \text { to } 2.51)^{\wedge}$ & 1.64 (1.10 to 2.46$) \#$ \\
\hline $\begin{array}{l}\text { Co-occurring } \\
\text { GIRLS }\end{array}$ & Ref & $1.07(0.67$ to 1.71$)$ & $1.32(0.84$ to 2.07$)$ & 1.76 (1.05 to 2.94$) \#$ \\
\hline Conduct-only & Ref & $0.89(0.53$ to 1.51$)$ & $1.73(1.14 \text { to } 2.61)^{\wedge}$ & 1.73 (1.06 to 2.83$)$ \\
\hline Hyperactivity-only & Ref & $1.23(0.88$ to 1.72$)$ & $1.35(0.96$ to 1.91$)$ & $1.39(0.95$ to 2.04$)$ \\
\hline Co-occurring & Ref & $0.26(0.08$ to 0.82$) \#$ & $0.69(0.26$ to 1.84$)$ & $1.05(0.51$ to 2.16$)$ \\
\hline
\end{tabular}

Differences statistically significant at $^{\wedge}=\mathrm{p}<0.01, \#=\mathrm{p}<0.05$

Table 4 Prevalence of behaviour problems: count (\%)

\begin{tabular}{|l|c|c|c|c|c|}
\hline & $\begin{array}{c}\text { Never } \\
\text { smoked }\end{array}$ & $\begin{array}{c}\text { Quit } \\
\text { smoking }\end{array}$ & $\begin{array}{c}\text { Light } \\
\text { smoker }\end{array}$ & $\begin{array}{c}\text { Heavy } \\
\text { smoker }\end{array}$ & $\begin{array}{c}\text { Total } \\
\text { count (\%) }\end{array}$ \\
\hline BOYS & & & & & \\
Conduct-only & $219(4.2 \%)$ & $52(5.5 \%)$ & $99(10.6 \%)$ & $97(15.9 \%)$ & $467(6.1 \%)$ \\
Hyperactivity-only & $447(9.6 \%)$ & $91(8.5 \%)$ & $109(12.6 \%)$ & $101(13.6 \%)$ & $748(10.1 \%)$ \\
Co-occurring & $141(2.7 \%)$ & $46(4.9 \%)$ & $56(6.0 \%)$ & $62(8.9 \%)$ & $305(3.9 \%)$ \\
Neither & $3981(83.6 \%)$ & $685(81.1 \%)$ & $685(70.8 \%)$ & $458(61.6 \%)$ & $5809(79.9 \%)$ \\
& & & & & \\
GIRLS & & & & \\
Conduct-only & $222(4.6 \%)$ & $59(5.7 \%)$ & $92(10.7 \%)$ & $101(13.5 \%)$ & $474(6.1 \%)$ \\
Hyperactivity-only & $250(5.4 \%)$ & $75(7.7 \%)$ & $70(9.3 \%)$ & $56(8.7 \%)$ & $451(6.4 \%)$ \\
Co-occurring & $95(1.9 \%)$ & $20(1.8 \%)$ & $31(3.2 \%)$ & $53(6.1 \%)$ & $199(2.4 \%)$ \\
Neither & $4046(88.1 \%)$ & $759(84.9 \%)$ & $653(76.8 \%)$ & $443(71.7 \%)$ & $5901(85.1 \%)$ \\
& & & & & \\
\hline
\end{tabular}

Note: All counts reported in table are un-weighted and percentages are weighted to correct for oversampling of poorer families. 


\section{DISCUSSION}

Our study suggests that persistent light and heavy smoking during pregnancy may play an aetiological role in conduct and hyperactivity-inattention problems in 3 year old boys, consistent with previous research in older age groups. ${ }^{2}$ The association with hyperactivity-inattention problems was not confined to boys who had co-occurring conduct problems. Girls whose mothers quit smoking during pregnancy had a lower risk of conduct problems than those whose mothers never smoked and, after excluding cooccurring hyperactivity-inattention problems, persistent smoking was associated with conduct-only problems in girls.

A possible limitation of the study is that the child's behaviour was reported by their mother, potentially producing bias; if mothers who reported smoking were more likely to under-report poor behaviour then this would attenuate the association. Future research in this cohort using teacher assessments of behaviour at older ages is needed to rule this out. Furthermore, maternal psychopathology, beyond the psychosocial characteristics already measured, should be collected in future MCS waves and controlled for in similar analyses.

Another possible limitation is under-reporting or denial of smoking due to strong social pressure on women not to smoke. If women who are more willing to admit to smoking are also more likely to have unmeasured characteristics which are independently associated with child behaviour problems, then we may have over-estimated the effect of smoking. However, previous work suggests that pregnant women's self-reports are reasonably accurate measures of smoking (compared to repeated assays of the metabolic 
by-products of smoking), particularly when interview based assessments of smoking patterns are used. ${ }^{30}$ Retrospective recall of exposure 9 months after pregnancy may have created recall bias, nevertheless a recent study found that retrospective reporting (mean 14 years after birth) was excellent relative to prospective measures and more likely to identify heavy smokers or those who quit during the first trimester. ${ }^{32}$ Furthermore, despite potential problems with ascertainment of smoking status, the four categories: never smoking during pregnancy, quitting, light and heavy smoking were clearly differentiated; virtually all less-favourable maternal characteristics became more frequent with more persistent and heavier smoking.

In addition to using four smoking categories, our study has a novel combination of strengths in areas with little previous research: the large sample size allowed us to examine girls and boys separately as young as 3 years old; to analyse singular behaviour problems in addition to their co-occurrence; and to control for a very broad range of potential confounding factors, without which a biased overestimation of risk may occur. ${ }^{29}$

We are unaware of other studies of exposure-related conduct and hyperactivity problems in children as young as 3 years old using the SDQ. Our results support other research suggesting that cigarette smoke is associated with precursors to disruptive behaviour in young children, including difficult temperament in infants aged 9 months, ${ }^{14}$ externalizing problems in toddlers aged 18 months, ${ }^{12}$ and physical aggression and defiance in children aged 3 years and younger. ${ }^{9-11}$ Two studies with much lower statistical power, report no significant associations between externalising behaviour of 3 year olds and smoking during pregnancy. ${ }^{37}$ Despite not reaching significance, the odds ratios for aggressive 
and inattention/hyperactivity problems in one study were 1.40 and 1.78 , respectively; similar to the present study. ${ }^{37}$

Pervious studies of sex differences in the association between smoking in pregnancy and conduct symptoms have found that associations are specific to boys, among children aged 4-18 years ${ }^{51519}$ but are associated with both sexes in pre-school children. ${ }^{70-12}$ Small sample sizes in the studies of preschool children may have constrained their ability to detect sex differences - the largest being $1,745,{ }^{10}$ compared to our sample of over 13,000 . This study also found associations with hyperactivity for both boys and girls, ${ }^{10}$ in contrast to our research. These studies focused on physical aggression and defiance, whereas our study covers a wider range of behaviours including tantrums, bullying, argumentativeness and spitefulness, as well as disobedience and fighting.

The majority of studies reviewed by Linnet et al ${ }^{24}$ and Button et al ${ }^{2}$ report associations between maternal smoking and hyperactivity-inattention, but other studies have found no relationship. 51920 We had hypothesised effects for conduct-only problems and cooccurring problems, but not for inattention-hyperactivity-only problems. ${ }^{912}$ Nevertheless, we note that associations we found for hyperactivity-inattention-only problems did not exhibit a dose-response relationship, additionally there were no associations for girls.

The significant associations between quitting and reduced risk of conduct problem or cooccurring problems for daughters supports findings relating to decreased risks to distress to novelty and irregularity in infants of quitters in the MCS. ${ }^{14}$ These results may be due to 
small numbers meeting the behaviour criteria. Nevertheless, the ability to quit may be an intergenerational characteristic of restraint and easy temperament.

Conversely, persistent and in particular heavy smoking throughout pregnancy may be a useful marker of families who need holistic support beyond pregnancy for a range maternal psychosocial problems, parenting, and everyday difficulties which continue to characterize these family environments 3 years after birth. Such support, in addition to targeted smoking cessation interventions, ${ }^{29}$ may minimise associated child behaviour problems.

Smoking during pregnancy may have direct effects on the development of behaviour problems, most plausibly via adverse teratological effects on the foetal development of brain structure and functioning, which is well-characterized in animal models. ${ }^{39}$ If boys' foetal development is more sensitive to these insults, then this would indicate why sons of smokers were more likely to have behaviour problems than daughters of smokers. Alternatively, smoking may be a marker for the intergenerational transmission of processes associated with both smoking during pregnancy and problems in offspring. If daughters of smokers are susceptible to genetic or family environmental influences linked to conduct problems but not to hyperactivity-inattention, then this may explain the significant risk of girls displaying conduct-only problems at this age. Rather than genes, exposure or environment being sole causes, the aetiology of disruptive behaviour disorders most likely involves gene-exposure-environment interactions. ${ }^{4041}$ Further research is needed to elucidate the genetic factors and aspects of family environment that 
increase the vulnerability of the child to any teratological insults resulting from exposure to cigarette smoke. 


\section{WHAT THIS PAPER ADDS}

\section{What is already known on this subject}

- Smoking during pregnancy has been consistently associated with abnormal conduct problems and hyperactivity-inattention in school-aged boys.

\section{What this study adds}

- Boys as young as 3 years old are at significant risk of displaying exposure-related conduct symptoms as measured by the Strength and Difficulties Questionnaire, after adjustment for an extensive range of social and psychosocial confounding factors.

- Three year old boys are at significant risk of displaying exposure-related hyperactivity-inattention symptoms even when these do not co-occur with conduct symptoms.

- Girls born to prenatal smokers are at significant risk of displaying conduct-only symptoms at 3 years old. However, girls born to quitters have a reduced risk of co-occurring conduct and hyperactivity-inattention problems. 


\section{Acknowledgements}

Kate Pickett is supported by a UK NIHR (National Institute of Health Research)

Career Scientist Award. Support for Drs Pickett and Wakschlag during the writing of this paper was also provided by grant 1RO1DA15223 from the US National Institute for Drug Abuse. Lauren Wakschlag is also supported by The Waldon and Jean Young Shaw Foundation and the Children's Brain Research Foundation. No sponsor had a role in the design or conduct of this study. The authors also thank the ESRC Data Archive at Essex University for providing the Millennium Cohort Study data, and members of the Millennium Cohort Study Users Group at the University of York.

\section{Copyright statement}

The Corresponding Author has the right to grant on behalf of all authors and does grant on behalf of all authors, an exclusive license on a worldwide basis to the BMJ Publishing Group Ltd and its Licensees to permit this article (if accepted) to be published in Journal of Epidemiology and Community Health and any other BMJPGL products to exploit its subsidiary rights, as set out in our license (http://jech.bmj.com/ifora/license.pdf)

\section{Competing Interest statement}

All authors declare that the answer to the questions on your competing interest form are all No and therefore have nothing to declare. 


\section{Contributors}

All authors participated in the design and writing of the study. JH conducted the analyses and is guarantor for the paper

Ethics approval was not required for this secondary analysis of anonymized data. 


\section{References}

1. BMA (British Medical Association), Board of Science and Education and Tobacco Control Resource Centre. Smoking and reproductive life: the impact of smoking on sexual reproductive and child health. London: BMA publications unit, 2004.

2. Button TM, Maughan B, McGuffin P. The relationship of maternal smoking to psychological problems in the offspring. Early Hum Dev 2007;83:727-32.

3. Wakschlag LS, Pickett KE, Cook Jr E, Neal LB, Bennett LL. Maternal smoking during pregnancy and severe antisocial behavior in offspring: A review. Am J Public Health 2002;92:966-74.

4. Maughan B, Taylor C, Taylor A, Butler N, Bynner J. Pregnancy smoking and childhood conduct problems: A causal association? J Child Psychol Psychiatry 2001;42:1021-8.

5. Weissman MM, WarnerV, Wickramaratne PJ, Kandel DB. Maternal smoking during pregnancy and psychopathology in offspring followed to adulthood. $\mathrm{J} \mathrm{Am}$ Acad Child Adolesc Psychiatry 1999;38:892-9.

6. Ashford J, Van Lier PA, Timmermans M, Cuijpers P, Koot HM. Prenatal smoking and internalizing and externalizing problems in children studied from childhood to late adolescence. , J Am Acad Child Adolesc Psychiatry 2008;47:779-87.

7. Hook B, Cederblad M, Berg R. Prenatal and postnatal maternal smoking as risk factors for preschool children's mental health. Acta Paediatr 2006;95:671-7.

8. Wakschlag LS, Keenan K. Clinical significance and correlates of disruptive behavior systems in environmentally at-risk preschoolers. J Clin Child Psychol 2001;30:262-75.

9. Huijbregts SC, Séguin JR, Zoccolillo M, Boivin M, Tremblay RE. Associations of maternal prenatal smoking with early childhood physical aggression, hyperactivity-impulsivity, and their co-occurrence. J Abnorm Child Psychol 2007;35:203-15.

10. Huijbregts SC, Séguin JR, Zoccolillo M, Boivin M, Tremblay RE. Maternal prenatal smoking, parental antisocial behavior, and early childhood physical aggression. Dev Psychopathol 2008;20:437-53.

11. Tremblay RE, Nagin DS, Seguin JR, Zoccolillo M, Zelazo PD, Boivin M, Perusse D, Japel C. Physical aggression during early childhood: Trajectories and predictors. Pediatr 2004;114:e43-50.

12. Wakschlag LS, Leventhal BL, Pine DS, Pickett KE, Carter AS. Elucidating early mechanisms of developmental psychopathology: The case of prenatal smoking and disruptive behavior. Child Dev 2006;77:893-906.

13. Brook JS, Brook DW, Whiteman M. The Influence of maternal smoking during pregnancy on toddlers' negativity. Arch Pediatr Adolesc Med 2000;154:381-5.

14. Pickett KE, Wood C, Adamson J, DeSouza L, Wakschlag LS. Meaningful differences in maternal smoking behaviour during pregnancy: implications for infant behavioural vulnerability. J Epidemiol Community Health 2008;62:318-24.

15. Fergesson D, Woodward L, Horwood L. Maternal smoking during pregnancy and psychiatric adjustment in late adolescence. Arch Gen Psychiatry 1998;55:721-7

16. Indredavik MS, Brubakk A-M, Romundstad P, Vik T. Prenatal smoking exposure and psychiatric symptoms in adolescence. Acta Paediatr 2007;96:37782. 
17. Maughan B, Taylor A, Caspi A, Moffitt TE. Prenatal smoking and early childhood conduct problems: testing genetic and environmental explanations of the association. Arch Gen Psychiatry 2004;61:836-43.

18. Silberg JL, Parr T, Neale MC, Rutter M, Angold A, Eaves LJ. Maternal smoking during pregnancy and risk to boys' conduct disturbance: an examination of the causal hypothesis. Biol Psychiatry 2003;53:130-5.

19. Wakschlag, LS, Hans SL. Maternal smoking during pregnancy and conduct problems in high-risk youth: A developmental framework. Dev Psychopathol 2002;14:351-69.

20. Wakschlag LS, Lahey R, Loeber R, Green S, Gorden R, Leventhal B. Maternal smoking during pregnancy and risk of conduct disorder in boys. Arch Gen Psychiatry 1997;54:670-6.

21. Wakschlag LS, Pickett KE, Kasza KE, Loeber R. Is prenatal smoking associated with a developmental pattern of conduct problems in young boys? J Am Acad Child Adolesc Psychiatry 2006;45:461-7.

22. Biederman J, Attention-deficit/hyperactivity disorder: a selective overview. Biol Psychiatry 2005;57:1215-20.

23. Langley K, Holmans P, van den Bree M, Thapar A. Effects of low birth weight, maternal smoking in pregnancy and social class on the phenotypic manifestation of Attention Deficit Hyperactivity Disorder and associated antisocial behaviour: investigation in a clinical sample. BMC Psychiatry 2007;7:26.

24. Linnet KM, Dalsgaard S, Obel C, Wisborg K, Henriksen TB, Rodriguez A, Kotimaa A, Moilanen I, Thomsen PH, Olsen J, Jarvelin M-R. Maternal lifestyle factors in pregnancy risk of Attention Deficit Hyperactivity Disorder and associated behaviors: Review of the current evidence. Am J Psychiatry 2003;160:1028-40.

25. Thapar A, Fowler T, Rice F, Scourfield J, van den Bree M, Thomas H, Harold G, Dale H. Maternal smoking during pregnancy and attention deficit hyperactivity disorder symptoms in offspring. Am J Psychiatry 2003;160:1985-9.

26. Mick E, Biederman J, Faraone SV, Sayer J, Kleinman S. Case-control study of Attention-Deficit Hyperactivity Disorder and maternal smoking, alcohol use, and drug use during pregnancy. J Am Acad Child Adolesc Psychiatry 2002;41:378-85.

27. Wakschlag LS, Pickett KE, Middlecamp MK, Walton LL, Tenzer P, Leventhal, BL. Pregnant smokers who quit, pregnant smokers who don't: does history of problem behavior make a difference? Soc Sci Med 2003;56:2449-60.

28. Weaver K, Campbell R, Mermelstein R, Wakschlag L. Pregnancy smoking in context: The influence of multiple levels of stress. Nicotine Tob Res 2008;10:1065-73.

29. Pickett KE, Wakschlag LS. Wilkinson RG. The Psychosocial context of pregnancy smoking \& quitting in the millenium cohort Study. J Epidemiol Community Health 2009;63:474-480.

30. Pickett KE, Rathouz PJ, Kasza K, Wakschlag LS, Wright R. Self-reported smoking, cotinine levels, and patterns of smoking in pregnancy. Paediatr Perinat Epidemiol 2005;19:368-76.

31. Pickett KE, Wakschlag LS, Dai L, Leventhal BL. Fluctuations of maternal smoking during pregnancy. Obstet Gynecol, 2003;101:140-7. 
32. Pickett KE, Kasza KE, Biesecker G, Wright RJ, Wakschlag LS. Women who remember, women who don't: A methodological study of maternal recall of smoking in pregnancy. In press: Nicotine Tob Res.

33. Dex S, Joshi H, eds. Children of the $21^{\text {st }}$ century: from birth to nine months. Bristol: Policy Press, 2005.

34. Centre for Longitudinal Studies. Millennium Cohort Study [1 June 2009]; http://www.cls.ioe.ac.uk/studies.asp?section=000100020001

35. Goodman R. Psychometric properties of the Strengths and Difficulties Questionnaire. J Am Acad Child Adolesc Psychiatry 2001;40:1337-45.

36. Kessler RC, Andrews G, Colpe LJ, Hiripi E, Mroczek, DK, Normand S-LT, Walters EE, Zaslavsky AM. Short screening scales to monitor population prevalences and trends in non-specific psychological distress. Psychol Med 2002;32: 959-76.

37. Whitaker RC, Orzol SM, Kahn RS. Maternal mental health, substance use, and domestic violence in the year after delivery and subsequent behaviour problems in children at age 3 years. Arch Gen Psychiatry 2006;63:551-60.

38. Teramoto S, Soeda A, Hayashi Y, Saito K, Urashima M. Problematic behaviours of 3-year-old children in Japan: Relationship with socioeconomic and family backgrounds. Early Hum Dev 2005;81:563-9.

39. Dwyer J, Broide R, Leslie F. Nicotine and brain development. Birth Defects Research Part C: Embryo Today: Reviews 2008;84:30-44.

40. Langley K, Turic D, Rice F, Holmans P, van den Bree MB, Craddock N, Kent L, Owen MJ. Testing for gene $\times$ environment interaction effects in attention deficit hyperactivity disorder and associated antisocial behavior. Am J Med Genet B Neuropsychiatr Genet 2008:147B:49-53.

41. Wakschlag LS, Kistner EO, Pine DS, Biesecker G, Pickett KE, Skol A, Dukic V, Blair RJ, Leventhal BL, Cox N, Burns J, Kasza KE, Wright RJ, Cook EH. Interaction of prenatal exposure to cigarettes and MAOA genotype in pathways to youth antisocial behavior. In press: Mol Psychiatry. 